\title{
Regime cambial para países emergentes: uma proposição a partir de Keynes ${ }^{1}$
}

\author{
Fernando Ferrari Filho ${ }^{2}$
}

\begin{abstract}
Resumo
O objetivo do presente artigo consiste em apresentar, tendo como referência a análise de Keynes, uma proposição de regime cambial para países emergentes que seja capaz de assegurar condições para a estabilização macroeconômica, entendida como o binômio estabilidade de preços e plenoemprego.
\end{abstract}

Palavras-chave: Taxa de câmbio; Economia keynesiana; Países emergentes.

\section{Abstract \\ Exchange rate regime for emergent countries: a Keynesian proposal}

The article presents, in a Keynesian perspective, a proposal of exchange rate regime for emerging countries to assure macroeconomic stabilization, that is, price stability and full employment.

Key words: Exchange rate regime; Keynesian theory; Emerging countries.

JEL E12, F33.

\section{Introdução}

Segundo os economistas do mainstream e os organismos financeiros internacionais, tais como o Fundo Monetário Internacional (FMI), o regime cambial usualmente definido como ideal para países emergentes é aquele representado por um mercado de capitais com elevado grau de abertura, em que a mobilidade de capitais seja absoluta, e um sistema de câmbio perfeitamente flexível (FMI, 2002).

Nesse regime, os ativos financeiros (títulos) domésticos são substitutos perfeitos dos títulos internacionais e, portanto, a paridade da taxa de juros doméstica com a taxa internacional define a eficácia da política monetária, qual seja: uma expansão monetária reduz a taxa de juros doméstica em níveis inferiores ao da taxa internacional, levando a uma fuga de capitais, com uma conseqüente desvalorização cambial, cujos efeitos positivos sobre as transações correntes acabam provocando uma expansão da demanda agregada, o que faz elevar a taxa de juros doméstica até que o equilíbrio do balanço de pagamentos seja

(1) Trabalho recebido em fevereiro de 2007 e aprovado em outubro de 2007.

(2) Professor titular da Universidade Federal do Rio Grande do Sul e pesquisador 1D do CNPq (Conselho Nacional de Desenvolvimento Científico e Tecnológico), Porto Alegre, RS, Brasil. E-mail: ferrari@ufrgs.br. O autor agradece pelos comentários e sugestões de Philip Arestis e dos pareceristas, isentando-os, todavia, dos erros remanescentes. 
restabelecido; efeitos simétricos são obtidos a partir de uma política monetária restritiva.

Em contrapartida, a necessidade de preservar as autonomias das políticas fiscal e, essencialmente, monetária dos países emergentes - diga-se de passagem, fundamentais para assegurar trajetórias de crescimento econômico sustentável e desenvolvimento social harmônico - tem reforçado os pontos de vista de economistas heterodoxos e alguns policy makers de que são necessárias a adoção de um regime cambial que evite a flutuação excessiva da taxa de câmbio e a implementação de controle de capitais.

Nos últimos anos, o debate em torno de regimes cambiais (flutuação cambial vis-à-vis câmbio administrado) e da manutenção ou liberalização de controle de capitais para países emergentes voltou ao centro das atenções, principalmente a partir dos desdobramentos das crises cambiais e financeiras do México (1994/1995), do Leste Asiático (1997), da Rússia (1998), do Brasil (1998/1999) e da Argentina (2001/2002). ${ }^{3}$

A principal constatação do referido debate é que a implementação de um regime cambial de livre flutuação e a ampla mobilidade de capitais, ainda que apoiada por uma política econômica responsável ou crível - em conformidade ao que apregoa o Consenso de Washington ${ }^{4}$-, tornam os países emergentes reféns dos humores e da lógica de curto prazo de acumulação desses capitais. Segundo o argumento convencional, a dificuldade enfrentada pelos referidos países é, via de regra, atribuir o comportamento volátil do financiamento externo à adoção de políticas econômicas irresponsáveis (Caramazza; Aziz, 1998). Por sua vez, segundo a visão heterodoxa, o resultado do binômio câmbio flutuante e mobilidade de capitais é que eles acabam atuando como fatores que desestabilizam e potencializam as crises cambiais nos países emergentes.

Diante dessa controvérsia, apresenta-se a seguinte questão: qual regime cambial é mais apropriado para os países emergentes operacionalizarem políticas

(3) As referidas crises cambiais e financeiras geraram um consenso, entre acadêmicos e policy makers, ao redor da necessidade de reestruturação do sistema monetário internacional como condição imprescindível para que a economia mundial e, em particular, os países emergentes voltem a experimentar períodos de expansão e prosperidade econômica. Se há um consenso em torno da necessidade de se reestruturar o sistema monetário internacional, não se pode, todavia, dizer o mesmo em relação aos mecanismos propostos para mitigar e/ou solucionar as instabilidades dos mercados cambiais e financeiros em nível mundial. Uma síntese das principais propostas de reestruturação do sistema monetário internacional pode ser encontrada em Eichengreen (1999, cap. 6-7), Eatwell e Taylor (2000); Davidson (1994, cap. 16; 2002, cap. 14) e Isard (2005, cap. 7-8).

(4) As medidas de caráter neoliberal preconizadas pelo Consenso de Washington para os países emergentes são as que seguem: (i) redução ou eliminação das barreiras alfandegárias; (ii) livre mobilidade de capitais, seja para investimentos estrangeiros, seja para as transações de moeda de conversibilidade; (iii) disciplina fiscal; (iv) reforma tributária; (v) desregulamentação financeira; e (vi) privatizações. 
econômicas que mantenham a inflação sob controle e viabilizem, sustentavelmente, o crescimento econômico?

Visando responder à referida questão, o objetivo do presente artigo consiste em apresentar, a partir da análise de Keynes, uma proposição de regime cambial para países emergentes que, ao ser capaz de mitigar suas vulnerabilidade e fragilidade externas e dependência em relação a capitais estrangeiros, assegure a estabilização macroeconômica - entendida, conforme Keynes (1964, cap. 24), como sendo o binômio estabilidade de preços e pleno-emprego. O argumento principal do artigo é o de que taxa de câmbio administrada e controle de capitais desempenham um papel importante para a estabilização macroeconômica dos países emergentes.

Para tanto, o artigo está dividido em três seções, além desta breve introdução. Na seção seguinte, resgatam-se as reflexões e proposições de Keynes pertinentes tanto à política cambial quanto à mobilidade de capitais, visando mostrar como contribuem para a estabilidade monetária e a manutenção do plenoemprego. Em seguida, após uma breve discussão sobre regimes cambiais alternativos e liberalização financeira ou controle de capitais, apresenta-se uma proposição de regime cambial com controle de capitais para países emergentes. Por fim, são apresentadas breves conclusões.

\section{Política cambial e mobilidade de capitais: uma análise keynesiana}

Ao longo da obra de Keynes são recorrentes suas preocupações com a reestruturação do sistema monetário internacional ${ }^{5}$ e, em particular, com o sistema de câmbio fixo, porém ajustável (à la crawling peg), e os mecanismos de controle de capitais fundamentais para assegurarem a autonomia da política econômica de modo a estabilizar o nível de preços e manter o crescimento econômico de plenoemprego.

É importante mencionar que a elaboração teórica de Keynes não é desvinculada da realidade, nem das questões práticas da política econômica. Muito pelo contrário, suas reflexões e proposições sempre foram condicionadas pelas transformações econômicas de seu tempo e estiveram associadas à sua atuação como policy adviser do governo inglês, entre 1910 e 1946. As questões cambial e de controle de capitais exemplificam isso: por um lado, em relação à política cambial, Keynes abandonou a proposta de uma forte rigidez, como eram as regras do sistema padrão-ouro, para uma política de taxa de câmbio administrada, pois entendia que a estabilidade cambial era de suma importância, tanto para a estabilização do sistema monetário internacional quanto para a estabilidade dos

(5) Sobre as reflexões e proposições de Keynes pertinentes à reforma do sistema monetário internacional, ver Ferrari Filho (2006, cap. 1). 
preços domésticos; por outro, embora Keynes fosse, inicialmente, favorável ao livre-comércio e à mobilidade plena dos fatores de produção, passou a defender, em face das mudanças ocorridas no período entre guerras, políticas comerciais protecionistas e controle de capitais.

A presente seção resgata, a partir de alguns trabalhos selecionados, as idéias de Keynes relacionadas à política cambial e à movimentação de capitais.

\subsection{Câmbio fixo-ajustável e autonomia da política monetária}

Em Indian Currency and Finance (Keynes, 1971a), publicado em 1913, Keynes, após uma análise comparativa minuciosa dos sistemas monetários gold standard e gold-exchange standard, propôs a adoção de um regime monetáriocambial à la gold-exchange standard, em que (i) a taxa de câmbio fosse fixa, mas ajustável, para assegurar relativa liberdade para a política monetária, tanto para estabilizar os níveis de preços quanto para dinamizar os níveis de renda e emprego, e (ii) houvesse a substituição gradual do ouro como moeda de reserva internacional por outras moedas administradas pelos bancos centrais nacionais. ${ }^{6}$

Em suma, na referida obra, Keynes apresentou uma proposta monetáriocambial que viabilizasse a estabilidade dos preços domésticos, a implementação de políticas econômicas expansionistas e uma maior elasticidade da oferta monetária mundial.

Com o abandono das regras do sistema monetário padrão-ouro ${ }^{7}$ e diante de um contexto em que todas as moedas européias passaram a flutuar livremente, Keynes passou a preocupar-se mais com a operacionalização do regime cambial e seu impacto tanto sobre a reestruturação do sistema monetário internacional quanto para a estabilidade monetária e, portanto, dos preços.

Em A Tract on Monetary Reform (Keynes, 1971b), publicado em 1923, a análise de Keynes vai na direção da idéia acima. Ao mostrar como as "variações no valor da moeda" afetavam as naturezas produtiva e distributiva das economias, Keynes criticou veementemente o sistema monetário padrão-ouro, pois tal sistema não mais garantia a estabilidade de preços e da taxa de câmbio, e defendeu operações de open market - portanto, política monetária ativa - como imprescindíveis para a estabilização das dinâmicas inflacionária e deflacionária. Nesse sentido, ele entendia ser necessária a subordinação da política cambial à dinâmica da política monetária. Nas palavras de Keynes, "quando a estabilidade

(6) Conforme Keynes (1971a, p. 71), as transações comerciais e financeiras do sistema monetário internacional não mais poderiam ser baseadas em ouro, pois sua elasticidade dependia da "descoberta e prospecção de novas reservas auríferas e (...) da mudança de idéias na Ásia”.

(7) O sistema monetário padrão-ouro é abandonado no início da Primeira Guerra Mundial. Nos anos 1920, houve algumas tentativas isoladas de restauração do referido sistema em determinados países. 
do nível de preços interno e a estabilidade da taxa de câmbio são incompatíveis, a primeira é geralmente preferível" (Ibid., p. 132).

O fato de ter sugerido a subordinação da política cambial à política monetária não quer dizer, todavia, que Keynes tenha deixado de se preocupar com a estabilidade da taxa de câmbio. Muito pelo contrário, para Keynes, por um lado, a estabilidade de preços seria fundamental para manter a taxa real de câmbio relativamente estável, em conformidade com a paridade do poder de compra, e, por outro, o "Banco da Inglaterra poderia regular, não fixar, o preço do ouro [e, portanto, a taxa de câmbio] (...) comprando e vendendo [reservas] de ouro (...) de maneira a manter inalterada [a taxa de câmbio] por consideráveis períodos" (Ibid., p. 149-150, ênfases adicionadas).

Em A treatise on money (Keynes, 1976), publicado em 1930, Keynes analisou as vantagens e desvantagens provenientes de regimes cambiais alternativos. Para ele, a discussão era pertinente na medida em que a adoção de um determinado regime cambial, por parte de um ou mais países, implicava o seguinte dilema: "preservar as vantagens da estabilidade das moedas locais dos países membros do sistema monetário internacional em termos de um padrão internacional [vis-à-vis] preservar a autonomia local de cada país membro no que diz respeito à sua política doméstica" (Ibid., v. 2, p. 304).

Naquela ocasião, Keynes propôs a adoção de um regime cambial à la crawling peg em que "cada país membro pudesse alterar o valor de sua moeda local em termos de ouro, a partir de uma determinada margem previamente estipulada, qual seja, 2,0\%" (Ibid., v. 2, p. 338).

Em Notes on the currency question (Keynes, 1982, p. 16-28), artigo escrito imediatamente após a Inglaterra ter abandonado o sistema monetário padrão-ouro e que, por conseqüência, subsidiaria seus argumentos quando de sua participação na Conferência Econômica Mundial, realizada em 1931, Keynes apresentou duas propostas de política cambial que não se afastariam das idéias explicitadas em A treatise on money, quais sejam: crawling peg system e fixação da libra esterlina a um padrão de valor básico (Ibid., p. 26-27).

Paralelamente, propôs um acordo de estabilização monetária angloamericana em que os movimentos na taxa de câmbio pudessem acompanhar as variações dos preços internacionais. ${ }^{8}$

(8) Essa proposta, baseada em The chaos of the foreign exchanges (Keynes, 1982, p. 259-263), tinha uma idéia básica, qual seja: variações cambiais deveriam acompanhar o diferencial inflacionário entre as economias americana e inglesa. Em outras palavras, a taxa real de câmbio deveria ser relativamente estável. 
Fernando Ferrari Filho

Em The means to prosperity (Keynes, 1972, p. 335-366), Keynes, ao apresentar uma proposta de reforma do sistema monetário internacional, intitulada Gold-Notes, sugeriu um arranjo monetário internacional tal que

cada país participante [do sistema monetário internacional] deveria previamente estabelecer uma (...) paridade relativamente fixa entre sua moeda e o ouro. [Por sua vez], as margens de compra e de venda de ouro por parte das autoridades monetárias domésticas não poderiam exceder a 5,0\% (...) bem como a paridade cambial deveria ser alterada (...) sempre que as circunstâncias econômicas assim exigissem (Ibid., p. 362).

No início da década de 1940, ao elaborar sua International Clearing Union (ICU), ${ }^{9}$ ou seja, uma proposição de reestruturação do sistema monetário internacional em que fossem asseguradas as condições de pleno-emprego da economia mundial no período após a Segunda Guerra Mundial, Keynes recomendou que os países que viessem a participar do referido sistema deveriam adotar um regime cambial de taxas fixas, porém ajustáveis, em relação ao padrão monetário internacional, bancor (Keynes, 1980, p. 170). Para ele, as flutuações nas taxas de câmbio teriam que ser discretas - intervalo de no máximo 5,0\% tanto para os países deficitários quanto para os países superavitários -, visando, assim, solucionar os desequilíbrios de balanço de pagamentos temporários. Nas palavras de Keynes,

[n]ós necessitamos de um método para determinar o valor da taxa de câmbio dos países (...) em que ações unilaterais tanto de apreciações quanto de depreciações cambiais possam ser evitadas (...) O objetivo é criar uma União Monetária, designada União Monetária Internacional, baseada em uma moeda internacional (...) bancor (...) fixa (porém flexível) em termos de ouro e aceita como equivalente ao ouro (Ibid., p. 168-170, ênfases originais).

Em suma, a partir de uma ligeira análise sobre as reflexões e proposições de Keynes acerca da política cambial, dois aspectos são particularmente relevantes: em primeiro lugar, Keynes entendia que a estabilidade cambial era fundamental para assegurar a estabilidade de preços; em relação ao segundo, apesar de Keynes entender que a adoção de um regime de taxas de câmbio fixas, mas ajustáveis, seria mais consistente em um contexto de uma ampla reestruturação do sistema monetário internacional, o regime cambial à la crawling peg era defendido tanto em um mundo de maior mobilidade dos fluxos de capitais, tal como aquele identificado com o sistema monetário padrão-ouro, quanto em situações internacionais de limitada mobilidade dos referidos fluxos, como o sugerido na ICU e o implementado após a Conferência de Bretton Woods. Em outras palavras, pela análise de Keynes, regimes cambiais administrados são

(9) É importante ressaltar que a ICU tornou-se o plano inglês quando das discussões sobre a reestruturação do sistema monetário internacional durante a Conferência de Bretton Woods, realizada em 1944. 
essenciais para os propósitos de estabilidade macroeconômica, entendida como o binômio inflação sob controle e crescimento econômico sustentável.

\subsection{Controle de capitais como instrumento de operacionalização de políticas econômicas de pleno-emprego}

Em The general theory of employment, interest and money (GT), Keynes mostra que, em economias monetárias, flutuações de demanda efetiva e no nível de emprego ocorrem porque, em um mundo no qual o futuro é incerto e desconhecido, os agentes econômicos preferem reter moeda e, por consequiência, suas decisões de gastos, sejam de consumo, sejam de investimento, são postergadas. Em outras palavras, a retenção de moeda, por parte dos agentes econômicos, se constitui em uma forma de segurança contra a precariedade do conhecimento em relação aos rendimentos esperados de seus planos de produção.

Uma vez que economias monetárias não necessariamente convergem para uma posição de equilíbrio de mercado, a intervenção extra-mercado - como controle e regulação - é fundamental para "conter as tendências imanentes à desagregação intrínsecas a economias de mercado" (Carvalho; Sicsú, 2006, p. 15), criando, assim, as condições propícias para o desenvolvimento de um ambiente institucional favorável às tomadas de decisões dos agentes econômicos.

Se, no âmbito de economias fechadas, se faz necessária a intervenção nos mercados, em nível internacional, devido ao fato de as transações comerciais e financeiras envolverem diferentes moedas, a regulação e o controle dos mercados se fazem muito mais necessários, pois a incerteza é mais exacerbada.

Tendo como referência essa idéia, percebe-se que todas as propostas de Keynes sobre a reforma do sistema monetário internacional têm um objetivo comum, qual seja: a criação, por parte de um international market maker, de uma moeda de liquidez internacional capaz de assegurar lastro para as tomadas de decisão de gastos dos agentes econômicos, tanto de consumo quanto de investimento, deixando, portanto, de ser um ativo especulativo e passível de entesouramento. Em outras palavras, a moeda de liquidez internacional, na visão de Keynes, apesar de ser um ativo com propriedades e características próprias às de um ativo monetário, teria como finalidades (i) propiciar a elasticidade necessária à expansão da produção e do comércio mundial e (ii) aportar os recursos necessários e suficientes para o processo de ajustamento, de curto prazo, do balanço de pagamentos das economias, dinamizando, assim, a demanda efetiva global.

Dentre as várias propostas de reforma do sistema monetário internacional apresentadas por Keynes, a mais elaborada encontra-se em sua ICU. Na referida proposição, Keynes argumentava que as discussões sobre a reestruturação do 
sistema monetário internacional deveriam estar centradas em torno da criação de um banco central mundial (ICU), emissor de uma moeda de liquidez internacional e padrão de valor estável. Essa Instituição, por sua vez, deveria ser capaz de (i) estabelecer regras monetário-cambiais, (ii) disciplinar a política comercial, (iii) reorganizar a dinâmica dos mercados, em termos de comportamentos de produção, distribuição e preços, (iv) regular os investimentos externos tanto de risco quanto dos fluxos de capitais de portfólio e (v) sinalizar regras de ajustamento de balanço de pagamentos (1980, p. 233-234). Em outras palavras, como, para Keynes, economias monetárias são inerentemente instáveis, ${ }^{10}$ a reestruturação do sistema monetário internacional a partir de um international market maker, com a capacidade de exercer as funções acima explicitadas, era imprescindível para que as decisões contratuais de gastos dos agentes econômicos fossem tomadas em um contexto de menor incerteza, imprevisibilidade, expandindo, por conseguinte, a demanda efetiva em nível mundial.

É nessa direção que Davidson (1994, 2002), partindo de uma taxonomia própria em que a dinâmica monetária em economias abertas pode ser tanto do tipo unionized monetary system (UMS) quanto do tipo non-unionized monetary system (NUMS), desenvolve uma proposta de reforma do sistema monetário internacional, denominada International Money Clearing Union (IMCU), cuja idéia consiste em mostrar que as propostas de Keynes pertinentes à reestruturação do sistema monetário internacional e, mais especificamente, de criação de uma moeda de reserva internacional administrada por um international market maker convergem para um sistema com as características de um UMS, quais sejam: taxas de câmbio relativamente fixas em relação ao padrão monetário internacional, contratos monetários expressos na moeda de reserva internacional e política monetária de flexibilização da liquidez internacional. A IMCU teria como objetivos, ao ampliar sua atuação na dinâmica econômica mundial, prevenir as crises de demanda efetiva, prover mecanismos automáticos de ajustamento (trigger mechanism) dos desequilíbrios de balanço de pagamentos, permitir que cada nação implementasse controles sobre fluxos de capitais e expandir a quantidade de liquidez internacional (Davidson, 1994, p. 268).

Os itens (iv) e (v) da ICU são as condições para que, conforme Keynes (1980: 176), "a tendência contracionista da economia mundial seja substituída por um processo expansionista".

Em relação a controles sobre fluxos de capitais, Keynes escreve que controle de movimentos de capital, tanto na entrada quanto na saída, deve ser uma tendência permanente do sistema econômico pós-Segunda Guerra Mundial (...)

(10) Conforme Keynes (1973, p. 411), "prosperidades e depressões são fenômenos peculiares a uma economia em que (...) moeda nunca é neutra". 
[todavia] controle de movimentos de capital não significa que o período de investimentos internacionais tenha terminado. Muito pelo contrário, o sistema [International Clearing Union] deve facilitar a restauração do crédito internacional (...) com vistas (...) à [expansão] de novos investimentos (...) e à manutenção do equilíbrio do balanço de pagamentos (Ibid., p. 185-187).

Para Keynes, controle de capitais era fundamental para preservar a autonomia da política monetária. Em suas palavras, "a administração da economia doméstica depende da liberdade de se operacionalizar uma taxa de juros apropriada sem referência às demais taxas de juros internacionais" (Ibid., p. 149).

Quanto à idéia de que os custos de ajustamento do balanço de pagamentos deveriam ser distribuídos entre os dois grupos de países, deficitários e superavitários, Keynes, opondo-se à sistemática do sistema monetário padrãoouro, em que todo o esforço de ajuste externo recaía sobre os países deficitários, argumenta que

[s]eria mais fácil, e com certeza mais satisfatório para todos os países, (...) que países com posições credoras em relação ao resto do mundo como um todo sofressem sanções econômicas, evitando, assim, que suas posições credoras exercessem pressões contracionistas sobre a economia mundial e, por consequiência, sobre suas próprias economias (Ibid., p. 178, ênfases originais).

Em conclusão, a implementação de uma proposta de reestruturação do sistema monetário internacional nas condições preconizadas por Keynes tem como objetivo assegurar a organização dos mercados em nível mundial. Nas palavras de Keynes (Ibid., p. 190-191), a ICU "utilizaria sua influência e seu poder para manter a estabilidade de preços e controlar o ciclo econômico".

\section{Câmbio administrado e controle de capitais como estratégias para os países emergentes}

Desde o colapso do sistema monetário internacional de Bretton Woods, no início da década de 1970, o processo de globalização, caracterizado pela crescente mobilidade internacional do capital e pela liberalização financeira, tem alterado substancialmente a dinâmica da economia mundial. Ademais, na ausência de políticas macroeconômicas para estimular o crescimento econômico e limitar os movimentos desestabilizadores dos fluxos de capitais, os fluxos internacionais de capitais especulativos têm criado sérios problemas monetários e cambiais para a economia mundial, especialmente para as economias emergentes. ${ }^{11}$

(11) A adoção, por parte das economias emergentes, de regimes de flutuação cambial, e a livre mobilidade de capitais têm desestabilizado e potencializado as crises cambiais dos referidos países, pois suas vulnerabilidade e fragilidade externas e dependência em relação a capitais estrangeiros os torna inerentemente instáveis. 
Como os arranjos institucionais da "era globalizada" não previnem as economias da ocorrência de crises monetário-cambiais e não existe um consenso político em torno da reestruturação do sistema monetário internacional, uma importante discussão na literatura macroeconômica, especialmente em países emergentes, está relacionada a qual é o regime cambial mais apropriado para os referidos países.

Alguns economistas (Edwards; Savastano, 2000; Edison; Levine; Ricci; Slok, 2002; Fischer, 1998; Obstfeld; Rogoff, 1995) argumentam que a flexibilidade da taxa de câmbio (i) equilibra, automaticamente, o balanço de pagamentos, (ii) reduz a vulnerabilidade externa e (iii) torna a política monetária autônoma, ao passo que a liberalização (i) aloca eficientemente a poupança (doméstica e externa), (ii) disciplina a política macroeconômica e (iii) melhora a performance do crescimento econômico. ${ }^{12}$

Para outros economistas, a necessidade de se preservarem as autonomias das políticas fiscal e monetária dos países - entendidas como fundamentais para assegurar trajetórias de crescimento econômico sustentável - tem reforçado os pontos de vista de alguns economistas e policy makers de que são necessárias a adoção de um regime cambial para evitar a flutuação excessiva da taxa de câmbio e a implementação de regulamentação sobre os fluxos de capitais. Ademais, Eichengreen e Leblang (2002) e Rodrik (1998) mostram que é difícil estabelecer uma relação causal consistente entre liberalização financeira e crescimento econômico robusto e estável, tanto para países desenvolvidos quanto, especialmente, para países emergentes.

Em relação a controle de capitais, por exemplo, as experiências recentes de adoção de controles de capitais por parte do Chile e da Malásia, no final dos anos 1990, da Índia e da China, desde o início da década de 1990, e da Argentina, a partir de 2005, influenciaram a discussão em torno do tema liberalização vis-àvis controle da conta capital e fizeram organismos financeiros internacionais, tais como FMI, revisarem suas posições, até então, amplamente favoráveis ao processo de liberalização de movimentos de capitais. ${ }^{13}$

(12) Cabe ressaltar que alguns economistas entendem que disciplinas fiscal e monetária são mais importantes do que a escolha do regime cambial. Veja, para tanto, Calvo e Mishkin (2003).

(13) No Chile, os controles de capitais desestimularam os capitais indesejáveis (aqueles de curta duração); na Malásia, eles foram implementados na saída de capitais; na China e na Índia eles são extensivos e têm limitado o processo de liberalização financeira; e na Argentina os capitais, com exceção de créditos comerciais e investimentos diretos externos, devem manter uma proporção de 30,0\% em depósitos não remunerados no Banco Central da Argentina. Veja, para tanto, Modenesi e Modenesi (2006) e Damil, Frenkel e Maurizio (2007). 
Diante dessa idéia e indo ao encontro das reflexões e proposições de Keynes apresentadas na primeira seção, ${ }^{14}$ entendemos que regimes de câmbio fixo-flexível e mobilidade imperfeita de capitais são mais apropriados para economias emergentes, uma vez que eles possibilitam a autonomia da política econômica doméstica, necessária para assegurar o pleno-emprego dessas economias.

Nesse sentido, o objetivo de se manter um câmbio menos volátil e mais competitivo em termos de comércio internacional torna interessante a adoção de regimes de câmbio intermediário - tais como um sistema à la crawling peg -, pois nesses regimes preserva-se a flexibilidade de ajuste de câmbio diante de choques, mas, ao mesmo tempo, se abrem possibilidades de orientação da trajetória temporal da taxa de câmbio. $\mathrm{O}$ funcionamento adequado desses regimes cambiais pode requerer, de modo tanto a evitar ataques especulativos quanto a aumentar a eficácia das autoridades monetárias na determinação da taxa de câmbio, a adoção de um regime de conversibilidade restrita da conta de capitais, isto é, a implementação de regulamentações sobre os fluxos de capitais.

No que diz respeito ao regime cambial, a adoção de uma taxa de câmbio em conformidade com o sistema crawling peg tem como objetivo fazer com que as incertezas empresariais em relação à volatilidade dos contratos futuros de câmbio sejam dirimidas e, por conseguinte, a demanda efetiva das economias emergentes, tanto interna quanto externa, seja expandida. A idéia consiste em estabelecer uma margem de flutuação ex ante da taxa de câmbio de maneira que a autoridade monetária possa intervir no mercado sempre que a taxa de câmbio se aproximar dos valores extremos, superior e inferior, da margem de flutuação previamente estabelecida. Assim sendo, a determinação prévia da flutuação da taxa de câmbio tem como finalidade influir nas expectativas dos agentes econômicos ao procurar reduzir a volatilidade do câmbio nominal e intervir em sua trajetória intertemporal, isto é, influir na determinação da taxa de câmbio real efetiva.

Concomitantemente à operacionalização de um regime cambial à la crawling peg, é necessário implementar mecanismos de controle de capitais, de maneira preventiva, da conta capital e financeira, utilizando, para tanto, um sistema moderno e eficiente de regulação de fluxos de capitais (Paula, 2003 e Carvalho; Sicsú, 2006). Em geral, os controles de capitais podem ocorrer de três

(14) É importante sublinhar que se tem ciência de que os problemas monetário-cambiais contemporâneos são muito mais complexos do que aqueles observados por Keynes décadas atrás. Ou seja, a economia global dos anos recentes é caracterizada por uma excessiva volatilidade cambial, pela mobilidade quase perfeita de capitais, pelos déficits de balanço de pagamentos dos Estados Unidos - diga-se de passagem, os Estados Unidos são, ainda, os responsáveis pela elasticidade da liquidez internacional - e pelas ações especulativas nos mercados financeiros, entre outras. 
maneiras: (i) controles administrativos, ou seja, restrição quantitativa de fluxos de capitais, conforme suas origens, maturidades e destinações; (ii) depósitos compulsórios incidentes sobre os fluxos de capitais ingressantes; e (iii) regulação financeira, isto é, imposição de limites sobre posições cambiais de residentes.

As propostas de controle de capitais variam desde a sugestão para um acordo internacional que institua um imposto único sobre os fluxos de capitais (o chamado "imposto Tobin") - cuja idéia básica é "jogar areia na engrenagem" do mercado financeiro, parafraseando uma analogia consagrada mundialmente (Eichengreen; Tobin; Wyplosz, 1995) - até iniciativas como a tributação sobre ingressos de capitais e o estabelecimento de prazos mínimos de permanência do capital (a chamada "quarentena"). Grenville (2000, p. 60), por exemplo, entende que a utilização de controles de capitais pode variar do modelo adotado pelo Chile (quarentena) até o modelo utilizado por Cingapura, que limitou a capacidade dos bancos domésticos de emprestarem para não residentes em moeda nacional, dificultando a tomada de posições vendidas na moeda doméstica pelos especuladores. Adicionalmente, sugere a adoção de controles prudenciais a fim de (i) limitar as oportunidades para os residentes tomarem emprestado em moeda estrangeira e (ii) manter uma forte restrição à capacidade dos bancos de abrirem posições em moeda estrangeira ou elevarem sua exposição em moeda estrangeira através dos empréstimos indexados à taxa de câmbio.

Portanto, a adoção de controles de capitais para economias emergentes tem dois objetivos: por um lado, restringir os fluxos de capitais implica reduzir a demanda por ativos em moeda conversível internacionalmente e, portanto, o potencial para a especulação contra a taxa de câmbio é significativamente reduzido; e, por outro lado, ao se evitar a excessiva flutuação da taxa de câmbio, obtém-se maior autonomia de política monetária.

\section{Conclusão}

Nos anos 1980 e 1990, a globalização econômica alterou substancialmente a natureza e os determinantes da dinâmica econômica mundial: a abertura das economias, a liberalização das contas financeira e de capital do balanço de pagamentos e, por conseguinte, a livre mobilidade de capitais de portfolio, a desregulamentação dos mercados financeiros domésticos e as inovações financeiras e as reformas estruturais liberalizantes - tais como a patrimonial e a previdenciária, objetivando o downsizing do setor público, e a trabalhista limitaram a ação das políticas macroeconômicas dos Estados Nacionais e foram um dos responsáveis pelas freqüentes crises de balanço de pagamentos e ataques especulativos às moedas nacionais dos países emergentes. Essa limitação e as recorrentes crises cambiais, por conseguinte, resultaram em flutuações cíclicas de demanda efetiva e elevação da taxa de desemprego da economia mundial, 
concentração da renda e do capital e exclusão social, fenômenos típicos do mundo contemporâneo. Assim sendo, devido (i) ao significativo aumento no volume e na velocidade de recursos no mercado financeiro internacional, (ii) à diluição nas fronteiras entre mercados e (iii) à maior integração entre os mercados financeiros em nível global, a dinâmica econômica nas referidas décadas ficou conhecida como processo de globalização financeira. ${ }^{15}$

A referida globalização, por sua vez, possui uma natureza disruptiva não somente em mercados domésticos, mas também sobre outros países, em especial os emergentes, criando uma espécie de cassino financeiro ampliado. Keynes, no capítulo 12 de sua $G T$, sustenta que há fortes conexões entre os setores financeiro e real da economia. Uma das conexões é o impacto da atividade especulativa sobre a atividade produtiva, especialmente sobre o investimento. Nesse particular, nunca é demais resgatar uma passagem da $G T$ na qual Keynes estabelece uma conexão entre os setores financeiro e real da economia. Segundo ele,

a posição é séria quando o empreendimento torna-se uma bolha sobre o redemoinho da especulação. Quando o desenvolvimento das atividades de um país torna-se o subproduto das atividades de um cassino, o trabalho provavelmente será malfeito (Keynes, 1964, p. 159).

$\mathrm{O}$ artigo mostrou que, em conformidade com a teoria keynesiana, é necessário que - em contexto de globalização financeira, ou seja, de maior interdependência econômica e maior intensidade no fluxo de capitais entre países - se criem condições para a operacionalização de políticas econômicas autônomas. Nesse particular, a despeito da ausência de uma instituição de cooperação monetária internacional que organize a economia mundial, a resposta à globalização econômica por parte dos países emergentes deve passar pela (i) criação de mecanismos que gerenciem as taxas de câmbio de forma a assegurar os objetivos domésticos de política econômica e prover um ambiente mais previsível para o investimento produtivo e a atividade produtiva em geral e (ii) implementação de controles de capitais de maneira a preservar a autonomia da política econômica, especialmente monetária.

Corroborando com a idéia acima, Ferrari Filho e Paula (2006, p. 219) mostram que, por exemplo,

China, Índia e Rússia, administrando seus regimes cambiais com conversibilidade restrita da conta de capital, têm sido casos, em maior ou menor grau, bemsucedidos de gerenciamento da política macroeconômica (...) [ao passo que] as estratégias de políticas econômicas adotadas na economia brasileira (...) de cunhos

(15) Cabe sublinhar que uma das conseqüências desse processo é a tendência de criação de um único mercado mundial de dinheiro e de crédito. Veja, para tanto, Ferrari Filho e Paula (2004).

Economia e Sociedade, Campinas, v. 17, n. 2 (33), p. 1-16, ago. 2008. 
Fernando Ferrari Filho

nitidamente liberalizantes, não conseguiram assegurar ao país um crescimento sustentável. ${ }^{16}$

Para finalizar, é importante ressaltar que regime cambial administrado e controle de capitais não são um fim em si mesmos, mas meios para se atingirem a prosperidade econômica, o pleno-emprego e uma distribuição de renda mais equiitativa entre indivíduos e entre países. Para tanto, conforme Davidson (1997, p. 672) argumenta, "prevenir crises é melhor do que remediá-las e, portanto, preveni-las deve ser o objetivo principal de longo prazo".

\section{Referências bibliográficas}

BENECKE, R.; NASCIMENTO, R. (Org.). Opções de política econômica para o Brasil. Rio de Janeiro: Fundação Konrad-Adenauer, 2003.

CALVO, G.; MISHKIN, F. The mirage of exchange rate regimes for emerging market countries. Journal of Economic Perspectives, v. 17, p. 99-118, 2003.

CARAMAZZA, F.; AZIZ, J. Fixed or flexible? Getting the exchange rate right in the 1990s. Washington, DC: IMF, 1998.

CARVALHO, F.C.; SICSÚ, J. Controvérsias recentes sobre controles de capitais. In: FERRARI FILHO, F.; SICSÚ, J. (Org.). Câmbio e controle de capitais: avaliando a eficiência de modelos macroeconômicos. Rio de Janeiro: Campus-Elsevier, 2006. p. 1-28.

DAMIL, M.; FRENKEL, R.; MAURIZIO, R. Macroeconomic policy changes in Argentina at the turn of the century. Nuevos Documentos Cedes, Buenos Aires, Cedes, 29, 2007.

DAVIDSON, P. Post Keynesian macroeconomic theory. Aldershot: Edward Elgar, 1994.

Are grains of sand in the wheels of international finance sufficient to do the job when boulders are often required? Economic Journal, v. 107, n. 442, p. 671-686, May 1997.

2002.

Financial markets, money and the real world. Cheltenham: Edward Elgar,

EATWELL, J.; TAYLOR, L. Global finance risk: the case of international regulation. New York: New Press, 2000.

EDISON, H.; LEVINE, R.; RICCI, L.; SLOK, T. International financial integration and economic growth. Journal of International Money and Finance, v. 21, p. 749-776, 2002.

EDWARDS, S.; SAVASTANO, M. Exchange rate in emerging economies: what do we know? What do we need to know? In: KRUEGER, A. (Ed.). Economic policy reform: the second stage. Chicago: University of Chicago Press, 2000. p. 453-510.

EICHENGREEN, B. Toward a new international finance architecture: a practical post Asia Agenda. Washington, DC: Institute for International Economics, 1999.

(16) As taxas médias anuais de crescimento do PIB de Brasil, Rússia, Índia e China, entre 2000 e 2006, foram, respectivamente, $3,1 \%, 6,6 \%, 6,4 \%$ e 9,5\%. Taxas calculadas tendo como referência as informações contidas no Ipeadata (2007) e no FMI (2007). 
EICHENGREEN, B.; LEBLANG, D. Capital account liberalization and growth: was Mahathir right? Washington, DC: NBER, Dec. 2002. (NBER Working Paper Series, n. 9247).

; TOBIN, J.; WYPLOSZ, C. Two cases for sand in the wheels of international finance. Economic Journal, v. 105, n. 428, p. 162-172, Jan. 1995.

FERRARI FILHO, F. Política comercial, taxa de câmbio e moeda internacional: uma análise a partir de Keynes. Porto Alegre: UFRGS Editora, 2006.

FERRARI FILHO, F.; PAULA, L. F. (Org.). Globalização financeira: ensaios de macroeconomia aberta. Petrópolis: Vozes, 2004.

Regime cambial, conversibilidade da conta capital e performance econômica: a experiência recente de Brasil, Rússia, Índia e China. In: FERRARI FILHO, F.; SICSÚ, J. (Org.). Câmbio e controle de capitais: avaliando a eficiência de modelos macroeconômicos. Rio de Janeiro: Campus-Elsevier, 2006. p. 184-221.

; SICSÚ, J. (Org.). Câmbio e controle de capitais: avaliando a eficiência de modelos macroeconômicos. Rio de Janeiro: Campus-Elsevier, 2006.

FISCHER, S. Capital-account liberalization and the role of the IMF. Essays in International Finance, v. 207, p. 1-10, 1998.

FUNDO MONETÁRIO INTERNACIONAL. World Economic Outlook. Sept. 2002. Disponível em: <http://www.imf.org.br>. Acesso em: set. 2002.

World Economic Outlook. Apr. 2007. Diponível em: <http://www.imf.org>. Acesso em: set. 2007.

GRENVILLE, S. Exchange rate regime for emerging countries. Reserve Bank of Australia Bulletin, Sidney, Reserve Bank, Nov. 2000.

INSTITUTO DE PESQUISA ECONÔMICA APLICADA. Disponível em: <http://www.ipeadata.gov.br>. Acesso em: set. 2007.

ISARD, P. Globalization and the International Financial System: what's wrong and what can be done. Cambridge: Cambridge University Press, 2005.

KEYNES, J. M. The general theory of employment, interest and money. New York, HBJ Book, 1964.

Indian currency and finance. London: Macmillan, 1971a. (The Collected Writings of John Maynard Keynes, v. 1).

A tract on monetary reform. London: Macmillan, 1971b. (The Collected Writings of John Maynard Keynes, v. 4).

. Essays in persuasion. London: Macmillan, 1972. (The Collected Writings of John Maynard Keynes, v. 9).

The general theory and after. London: Macmillan, 1973. (The Collected Writings of John Maynard Keynes, v. 13).

A treatise on money. New York: AMS Press, 1976. 
Fernando Ferrari Filho

KEYNES, J. M. Activities 1920-1922: treaty revision and reconstruction. Edited by E. Johnson. London: Macmillan, 1977. (The Collected Writings of John Maynard Keynes, v. 17).

Activities 1940-1944: shaping the post-war world, the Clearing Union. Edited by D. Moggridge. London: Macmillan, 1980. (The Collected Writings of John Maynard Keynes, v. 25).

Activities 1931-1939: world crisis and policies in Britain and America. Edited by D. Moggridge. London: Macmillan, 1982. (The Collected Writings of John Maynard Keynes, v. 21).

KRUEGER, A. (Ed.). Economic policy reform: the second stage. Chicago: University of Chicago Press, 2000.

MODENESI, A. M.; MODENESI, R. L. Controle de capitais: uma proposta de esquerda? In: FERRARI FILHO, F.; SICSÚ, J. (Org.). Câmbio e controle de capitais: avaliando a eficiência de modelos macroeconômicos. Rio de Janeiro: Campus-Elsevier, 2006. p. 58-85.

OBSTFELD, M.; ROGOFF, K. The mirage of fixed exchange rates. Journal of Economic Perspectives, v. 9, p. 73-96, Fall 1995.

PAULA, L. F. Controle de capitais: lições para o Brasil. In: BENECKE, R.; NASCIMENTO, R. (Org.). Opções de política econômica para o Brasil. Rio de Janeiro: Fundação Konrad-Adenauer, 2003. p. 435-455.

RODRIK, D. Who needs capital-account convertibility? Essays in International Finance, 207, p. 55-65, 1998. 